\title{
Introduction to Simulating the Past
}

\author{
Marco Madella • Bernardo Rondelli • \\ Carla Lancelotti • Andrea Balbo • Debora Zurro • \\ Xavi Rubio Campillo • Sebastian Stride
}

Published online: 26 April 2014

(C) Springer Science+Business Media New York 2014

Keywords Modelling Simulation · Archaeology · Human behaviour

It is in creating the artificial and controllable that science excels (R.E. Gomory)

\section{Why This Issue}

This is the introduction to a special issue of Journal of Archaeological Method and Theory focusing on modelling and simulation in archaeology.

Archaeology is a discipline based on abductive reasoning, where the premises do not guarantee the conclusions. In other words, hypotheses in archaeology are generated on the basis of an incomplete set of observations, and the discovery or the acquisition of new information can modify the previously developed hypotheses. Abductive reasoning is a useful tool for developing explanations that are adequate to describe an

\footnotetext{
M. Madella $(\bowtie)$

ICREA/Complexity and Socio-Ecological Dynamics (CaSEs), Universitat Pompeu Fabra and IMF-CSIC, Barcelona, Spain

e-mail: marco.madella@icrea.cat

B. Rondelli $\cdot$ A. Balbo $\cdot$ D. Zurro

CaSEs, IMF-CSIC, Barcelona, Spain

C. Lancelotti

CaSEs, Department of Information and Communications Technologies, Universitat Pompeu Fabra, Barcelona, Spain

X. R. Campillo

Barcelona Supercomputing Centre, Barcelona, Spain

S. Stride

Department of Prehistory, Ancient History and Archaeology, Universidad de Barcelona, Barcelona, Spain

B. Rondelli · S. Stride

Siris Academic, Barcelona, Spain
} 
observed phenomenon. However, without further testing, such explanations remain adequate but are not necessarily accurate.

The importance of abductive reasoning in archaeological research justifies the major efforts and investments dedicated to data gathering and to the improvement of analytical methods over the past decades (i.e. from the advent of New Archaeology onwards). In contrast, few resources have been dedicated to develop a sound methodology that supports the process of inferential reasoning per se, to make it consistent and repeatable and generating explicit and reusable models. In practical terms, archaeologists tend to build their hypotheses using the available data, often selecting a subset and rarely explicating the details of the model used to reach their conclusions. Furthermore, in some cases, the formal consistence and coherence of the proposed models are not explored.

These shortcomings are particularly evident when considering that archaeologists are constantly dealing with complex and dynamic situations where the non-explicit models are used to study changes and processes. In doing so, the significance of equifinality (Premo 2010) and uncertainty (Crema 2012) is rarely pondered, simply because archaeologist seems to consider these parameters as intractable problems. On the contrary, we argue that these problems are not so intractable and that they can be tackled with a different methodology, less focused on data gathering and data analysis and more oriented towards model building and inferential reasoning. We do not consider these two realities as antagonistic; on the contrary, we believe that they are two sides of the same coin, and they both deserve to be explored and integrated.

Building a model consists in building a representation of the structure and functioning of the system under study (Epstein 2008). It is also, in a sense, the formalisation of a chain of reasoning about the pegs and cogs of the system of interest. Significantly, a model has to be at the same time similar to and simpler than the system under study. Indeed, it has to contain all the salient features of the system, while being less complex, to make it understandable. In this sense, a useful model is the best compromise between realism and minimalism. Once this formalisation and simplification are achieved, we can carry out trials exploring the dynamics of the model using simulation. In other words, simulating a system means putting into operation the model of the system. Simulation can be seen as a multifaceted tool: (1) a technique to investigate the dynamics of a system; (2) a heuristic tool to develop hypotheses and theories; (3) a pedagogical tool to understand a process and to divulge its understanding and finally (4) an experimental tool to produce new scenarios. Computer simulation is, indeed, a kin to running an experiment, the model can be reconfigured, and parameter's values changed as many times as needed, something that would be totally impractical or impossible in the real world. By observing how the model operates, we are able to understand its properties by inference from the behaviour of the system. Therefore, a simulation is primarily an instrument to assess the working of a system, under different parameter values that are of interest for our investigation, and over long periods of time.

Despite the steep increase of the application of computer simulation in many fields over the last 40 years, its impact in archaeology has been minimal, and the researchers exploring this methodology are considered a kind of fringe movement (see Costopoulos and Lake 2010, Lake 2014, McGlade 2014). The increased availability of simple software environments together with the publication of models implemented in "accessible" languages, and a growing interdisciplinary interest in Social Sciences, is 
currently changing this situation by widening the community with access to this tool. Furthermore, the implementation of supercomputing (parallel and cloud) raised hopes for using computer simulation to approach complex problems arising from human behaviour. As a result, the number of challenging opportunities for rethinking the role of computer simulation specifically in archaeology is rapidly growing.

\section{The SimulPast Project: A Methodological Challenge}

In December 2010, a 5-year, blue-sky research project (SimulPast www.simulpast.es) seeking at developing an innovative and interdisciplinary methodological framework for modelling and simulating ancient societies was funded by the Spanish government. SimulPast has been inspired by archaeology but integrates knowledge from diverse fields such as anthropology, computer sciences, environmental sciences, physics, mathematics and sociology with the ambition to generate methodological guidelines for integrating the use of computer simulation in the study of the past (Madella and Rondelli 2012; Caro et al. 2013). The origin of the project was in the realisation, by a group of researchers with diverse archaeological backgrounds, which over the year's important progress was made in the acquisition of better, more meticulous and/or more reliable archaeological data. However, this advancement did not match a similar progress in the understanding of the processes and mechanisms that are behind such data, and the deductions that could be drawn from their analysis. To comprehend processes and mechanisms, we need to move into a more experimental ambit, and to do so, we need to improve our capability of building models specifically for studying human behaviour with a focus on social transformations. SimulPast research is inspired from a series of significant case studies from diverse geographical areas (South America to Europe, the Near East and Asia) with a chronological framework covering the current interglacial period, i.e. the Holocene (c. $13 \mathrm{ka}$-present). These case studies were selected to provide a collection of realities from which to develop our theoretical and methodological proposal.

The project aims to approach and possibly solve a series of methodological challenges that are currently open or greatly debated questions in the context of computer simulation in social sciences:

- The use of computer simulation for theory building versus hypothesis testing, or in other words, exploratory versus explanatory models. Are the two approaches completely incompatible or can we identify hybrid solutions? And, are hybrid solutions useful?

- The possible added value of realistic versus abstract simulation. What are the advantages, if any, of simulation inspired by realistic data? Which is the right scale for complexity reduction? How can we build empirically based simulations?

- Model-based versus rule-based. Is the introduction of complex decision-making algorithms and cognitive models useful (and computationally feasible) for understanding cultural processes?

- Validation/tuning and fitting of simulation experiments. Does a coherent and consistent way of validating simulation results for archaeological problems really exist? 
- Is it fundamental that models can be replicated and thus useful beyond the case study from which they are generated? How do we document and communicate the models? And how can we make the results easily readable and understandable?

All these challenges have been the object of disciplinary studies and reflexions (e.g. in archaeology, sociology, computer sciences, ecology and physics). However, a common interdisciplinary debate is still missing, and it is in this context that SimulPast intends to act. The project works as a common ground in which archaeologists, sociologists, computer scientists, ecologists and physicists explore the limits and the potentialities of computer simulation for studying social change. From an approach in which the different stakeholders (including the public through our dissemination programme) are able to intervene in and inspire the methodological developments, we hope to create a transdisciplinary reality for an improved environment for the use of computer simulation exploring past human behaviour in a wider perspective. As the Gulbenkian Commission predicted (Wallerstein 1996), much of the most interesting and exciting research over the last couple of decades has been done outside the boundaries of the narrowly defined traditional disciplines. The ambition of our work within the frame of the project SimulPast is to move beyond single discipline knowledge clusters, and we have conceived this special issue as a step in this direction.

\section{This issue's Contributions}

This issue presents a collection of works arising from the diverse research groups of the SimulPast project, complemented by invited expert contributions. Our aim was to give the reader a snapshot of the current research in modelling and simulation in archaeology.

Lake's paper opens this issue providing the reader with a comprehensive history of the recent applications of simulation in archaeology. This critical review concentrates on the variety of approaches to simulation in archaeology, particularly in the last 15 years. The author wonders about the unbalanced application of simulation, where the biological side (as in human evolution) has greatly benefitted from simulation while the more "sociological" aspect of archaeological simulation remains a challenge. In contrast, McGlade's article provides a stimulating critic to the use of modelling in archaeology, and in particular, to what the author considers the overvalued approach of agent-based simulation. McGlade argues for the use of simulation as a laboratory for exploration of social system dynamics and emphasizes the use of modelling to support archaeological narratives. Barton's (2014) contribution is the first paper of the collection to offer a tangible application of archaeological simulation, where a computational model of a subsistence agriculture small-scale society is used to illustrate the level of complexity in a small-scale society and the potential for new modelling methods to assist archaeological inquiries.

Cooperative behaviour has been thoroughly explored in social sciences for its role in the evolution of the human species and as a major mechanism of social relationships. Salgado et al. (2014) explore the evolutionary mechanisms behind the selection of cooperative behaviour and the potential of ABM to perform highly abstract experiments to connect these mechanisms to the observed patterns. This is a powerful tool for 
exploring behavioural evolution and the intervening social mechanisms. Briz Godino et al. (2014) contribution, also on cooperation, discusses the need to include in the modelling process stronger theoretical foundations based on empirical observation of the archaeological and historical record. Their agent-based modelling work is inspired by ethnographic sources and it is used to explore the role of cooperation in a hunterfisher-gatherer society, the Yamana, where individuals face the social dilemma of exclusively exploiting or sharing a highly profitable but punctual and unpredictable resource such as beached whales. The use of archaeological data to inspire and calibrate models is also debated in Del Castillo et al. (2014), a paper focusing on the emergence of ethnicity and cultural differentiation in the hunter-gatherer groups of Patagonia. This contribution illustrates a work in progress on the use of an agent-based model to explore the consequences that labour exchange and territorial mobility have on identity formation and cultural diversity.

Crema (2014) proposes a different approach, where abstract agent-based simulation is used for understanding long-term changes in human settlement patterns. The author argues for the construction of an abstract model developed from a simple heuristic approach where universal assumptions, inspired from the ecological literature, are combined in silico to lower the risk of generating ad hoc complex models that could be hardly explored exhaustively. On the same line of approach is the paper from Angourakis et al. (2014) which illustrates an abstract, theory building agent-based model that explores mechanisms of land use competition between the economical strategies of farming and herding (where the agent is the land-use strategies rather than the people behind them). The oasis construction process of Central Asia inspires this work, and the authors are interested in exploring the influence of aggregate decisions (i.e. mobility, intensity and interdependence of activities) on the dynamics of land use patterns. The results of this abstract model are then used as the basis to discuss historical and archaeological implications for Central Asia oases.

Balbo et al. (2014) propose a hybrid approach. In this contribution, palaecolimatic and environmental data are used to generate a realistic scenario for the semi-arid environment of Northern Gujarat (India). Subsequently, an agent-based model is used to explore the effects of climate change on the population dynamics of Holocene hunter-gatherer communities. The paper of Balbo et al. (2014) is a substantial step towards the integration of social, ecological and climatic parameters in a single computer model. In fact, while computer simulation has become common practise for the study of climate trends (e.g. Andersen et al. 2004; Clement and Peterson 2008; Mayewsky et al. 2004), important limitations still exist for the integration of the social and ecological components (Dearing et al. 2011). Isern et al. (2014) explore the spacetime dynamics of the Neolithisation process in Europe at a regional scale (the Iberian Peninsula) through equation-based modelling. This contribution is a remarkable example of equation-based modelling used to explore the introduction of an economic trait (agriculture) and its expansion in a geographical area characterised by physiographical constrains (e.g. mountains and rivers).

Ortega et al. (2014) explore an alternative approach, through ABM modelling, to challenge models such as the law of monotonic decrement or the down-the-line model for prehistoric goods exchange (Renfrew 1975). The study focuses on obsidian exchange networks in the Near East starting from the Pre-Pottery Neolithic period. These systems of goods exchange are regarded as complex networks, and ABM is used to 
explore the roles of parameters such as population density or collaboration in dynamics of long distance transfer. Finally, Barceló et al. (2014) introduce a model contributing towards the understanding of social mechanisms related to the spread of populations (demic diffusion models), the spread of ideas (cultural transmission models) and the spread of goods (innovation diffusion model).

\section{Concluding Remarks}

The use of modelling and simulation in archaeology and social sciences with the aim of exploring traits of human behaviour is still a relatively new discipline. Thus, it is constantly transforming and adapting to the new challenges that characterise innovative lines of research. The academic community involved in this work is constantly put to the test as to how to overcome theoretical and technical drawbacks. Many problems still exist, and discussion is ongoing, for example on whether realistic models are useful and scientifically valid. At the same time, reading the papers in simulation, it is clear that the effective communication of simulation results in a clear, consistent but readable form is still an open challenge.

In spite of the remaining open questions, the contributions to this volume visibly demonstrate that this avenue of research is instrumental in advancing our knowledge on the evolution of human behaviour. Projects like SimulPast, from which this collection of paper originates, are essential to promote an integrated approach and to create robust and reliable tools for the behavioural studies of our species.

Acknowledgments The SimulPast project is funded by the Spanish Ministry of Economy and Competitiveness/Ministry for Science and Innovation (grant CSD-2010-00034) and benefits from the Spanish post-doctoral programme Juan de la Cierva and the EU post-doctoral programme of the Marie SkłodowskaCurie Actions.

\section{References}

Andersen, K. K., Azuma, N., Barnola, J. M., Bigler, M., Biscaye, P., Caillon, N., et al. (2004). High-resolution record of Northern Hemisphere climate extending into the last interglacial period. Nature, 431(7005), 147-151.

Angourakis, A., Rondelli, B., Stride, S., Rubio-Campillo, X., Balbo, A. L., Torrano, A., et al. (2014). Land use patterns in Central Asia. Step 1: the musical chairs model. Journal of Archaeological Method and Theory, 21(2). doi:10.1007/s10816-013-9197-0.

Balbo, A. L., Rubio-Campillo, X., Rondelli, B., Ramírez, M., Lancelotti, C., Torrano, A., Salpeteur, M., Lipovetzky, N., Reyes-García, V., Montañola, C., Madella, M. (2014). Agent-based simulation of Holocene Monsoon precipitation patterns and hunter-gatherer population dynamics in semi-arid environments. Journal of Archaeological Method and Theory, 21(2). doi:10.1007/s10816-014-9203-1.

Barceló, J. A., Capuzzo, G., Bogdanović, I. (2014). Modeling expansive phenomena in early complex societies: the transition from Bronze Iron Age in Prehistoric Europe. Journal of Archaeological Method and Theory, 21(2). doi:10.1007/s10816-013-9195-2.

Barton, C. M. (2014). Complexity, social complexity, and modeling. Journal of Archaeological Method and Theory, 21(2). doi:10.1007/s10816-013-9187-2.

Briz i Godino, I., Santos, J. I., Galán, J. M., Caro, J., Álvarez, M., Zurro, D. (2014). Social cooperation and resource management dynamics among late hunter-fisher-gatherer societies in Tierra del Fuego (South America). Journal of Archaeological Method and Theory, 21(2). doi:10.1007/s10816-013-9194-3. 
Caro Saiz, J., Zurro, D., Rondelli, B., Rubio Campillo, X., Balbo, A., Barceló, J. A., Briz Godino, I., Fort, J., Madella, M. (2013). SimulPast: un laboratorio virtual para el análisis de las dinámicas históricas. Archeologia e Calcolatori, 24 (2013).

Clement, A. C., \& Peterson, L. C. (2008). Mechanisms of abrupt climate change of the last Glacial period. Reviews of Geophysics, 46, 1-39.

Costopoulos, A., \& Lake, M. W. (2010). Simulating change: Archaeology into the twenty-first century. Salt Lake City: The University of Utah Press.

Crema, E. R. (2012). Modeling temporal uncertainty in archaeological analysis. Journal of Archaeological Method and Theory, 19(3), 440-461.

Crema, E. R. (2014). A simulation model of fission-fusion dynamics and long-term settlement change. Journal of Archaeological Method and Theory, 21(2). doi:10.1007/s10816-013-9185-4.

Dearing, J., Dotterweich, M., Newman, L., \& Gunten, L. V. (2011). Integrative Paleoscience for sustainable management. PAGES News, 19(2), 43.

del Castillo, F., Barceló, J. A., Mameli, L., Miguel, F., Vila, X. (2014). Modeling mechanisms of cultural diversity and ethnicity in hunter-gatherers. Journal of Archaeological Method and Theory, 21(2). doi:10. 1007/s10816-013-9199-y.

Epstein, J. M. (2008). 'Why Model?'. Journal of Artificial Societies and Social Simulation, 11(4/12) <http:// jasss.soc.surrey.ac.uk/11/4/12.html $>$.

Gomory, R. (1995). The known, the unknown and the unknowable. Scientific American, 272(6), 120.

Isern, N., Fort, J., Carvalho, A. F., Gibaja, J. F., Ibañez, J. J. (2014). The neolithic transition in the Iberian Peninsula: data analysis and modeling. Journal of Archaeological Method and Theory, 21(2). doi:10. 1007/s10816-013-9193-4.

Lake, M. W. (2014). Trends in archaeological simulation. Journal of Archaeological Method and Theory, 21(2). doi:10.1007/s10816-013-9188-1.

Madella, M. \& Rondelli (2012). Social and environmental transitions: Simulating the past to understand human behaviour (SimulPast). In F. Bertoncello and F. Braemer (Eds.), Variabilités environnementales mutations sociales - Nature, intensités, échelles et temporalités des changements. XXXIIe Rencontres internationales d'archéologie et d'histoire d'Antibes (126-138). Antibes: Editions APDCA.

Mayewski, P., Rohling, E., \& Stager, J. C. (2004). Holocene climate variability. Quaternary Research, 62, $243-255$.

McGlade, J. (2014). Simulation as narrative: contingency, dialogics, and the modeling conundrum. Journal of Archaeological Method and Theory, 21(2). doi:10.1007/s10816-014-9201-3.

Ortega, D., Ibañez, J. J., Khalidi, L., Méndez, V., Campos, D., Teira, L. (2014). Towards a multi-agent-based modelling of Obsidian exchange in the Neolithic Near East. Journal of Archaeological Method and Theory, 21(2). doi:10.1007/s10816-013-9196-1.

Premo, L. S. (2010). On the role of agent-based modeling in post-positivist archaeology. In A. Costopoulos \& M. Lake (Eds.), Simulating change: Archaeology into the 21st Century (pp. 28-37). Salt Lake City: University of Utah Press.

Renfrew, C. (1975). Trade as action at a distance: Questions of integration and communication. In J. A. Sabloff \& C. C. Lamberg-Karlovsky (Eds.), Ancient civilization and trade, school of american research (pp. 3-60). Albuquerque: University of New Mexico Press.

Salgado, M., Noguera, J. A., Miguel, F. J. (2014). Modelling cooperation mechanisms: some conceptual issues. Journal of Archaeological Method and Theory, 21(2). doi:10.1007/s10816-013-9186-3.

Wallerstein, I. (1996). Open the social sciences: Report of the Gulbenkian Comission on the restructuring of the social sciences. Stanford: Stanford University Press. 